\title{
Synthesis of Large Arrays of Well-Aligned Carbon Nanotubes on Glass
}

\author{
Z. F. Ren,* Z. P. Huang, J. W. Xu, J. H. Wang, P. Bush, \\ M. P. Siegal, P. N. Provencio
}

\begin{abstract}
Free-standing aligned carbon nanotubes have previously been grown above $700^{\circ} \mathrm{C}$ on mesoporous silica embedded with iron nanoparticles. Here, carbon nanotubes aligned over areas up to several square centimeters were grown on nickel-coated glass below $666^{\circ} \mathrm{C}$ by plasma-enhanced hot filament chemical vapor deposition. Acetylene $\left(\mathrm{C}_{2} \mathrm{H}_{2}\right)$ gas was used as the carbon source and ammonia $\left(\mathrm{NH}_{3}\right)$ gas was used as a catalyst and dilution gas. Nanotubes with controllable diameters from 20 to 400 nanometers and lengths from 0.1 to 50 micrometers were obtained. Using this method, large panels of aligned carbon nanotubes can be made under conditions that are suitable for device fabrication.
\end{abstract}

Since the first observation of carbon nanotubes ( $I$ ), numerous papers have reported studies on the yield of well-graphitized nanotubes, their diameter and wall thickness (singlc or multiple) (2-4), growth mechanisms (5), alignment (6-8), electron emission propertics $(9-1 /)$, nanodevices $(12,13)$, theoretical predictions (14), and potential applications (14). Alignment of the carbon nanotubes is particularly important to enable both fundamental studies and applications, such as colil-conliocle flat pancl displays and vncuum microclectronics. 'lliere was little suceess in obtaining alignment of carbon nanotubes on large areas until the report on the growth of aligned carbon nanotubes on mesoporous silicil containing iron manoparticles via thermal dccomposition of acetylene gas in nitrogen gas at temperatures above $700^{\circ} \mathrm{C}(7)$. However, this ligh growth temperature makes this method unsuitable for the fabrication of carbon nanotubes on glass, because the strain point of the best display glass is $666^{\circ} \mathrm{C}(15)$.

Recently, we have successfully grown large-scale well-aligned carbon nanotubes on nickel foils at temperatures below $700^{\circ} \mathrm{C}$ (16). Here we report the growth of largescale well-aligned carbon nanotube arrays on glass at temperatures below $666^{\circ} \mathrm{C}$. These lower temperalure growth conditions are suitable for electron enission applications, such as cold-cathode flat pancl displays, which resuire eatson natnotube emillens grown per-

Z. F. Ren, Z. P. Huang, J. W. Xu, J. H. Wang, Materials Synthesis Laboratory, Natural Sciences Complex, Departments of Physics and Chemistry, and Center for Advancef Photonic and Electronic Materials, State University of New York, Buffalo, NY 14260-3000. USA. P. Bush, Instrumentation Center, State University of New York, Buffalo, NY 14214, USA. M. P. Siegal and P. N. Provencio, Sandla National Laboratories, Albuquerque, NM 87185-1421, USA.

*To whom correspondence should be addressed: Email: zren@acsu.bulfalo.edu pendicular to the glass surface. The carbon nanotube arrays are fabricated by first depositing a thin nickel layer onto display glass by radio frequency (rf) magnetron sputtering (17). The carbon nanotubes are then grown on the nickel-coated display glass by plasmaenhanced hot filament clemical vapor deposition (PE-HF-CVD) (I7).

Scanning electron microscopy (SEM) was used to investigate the effect of various growth conditions on the morphology of car-
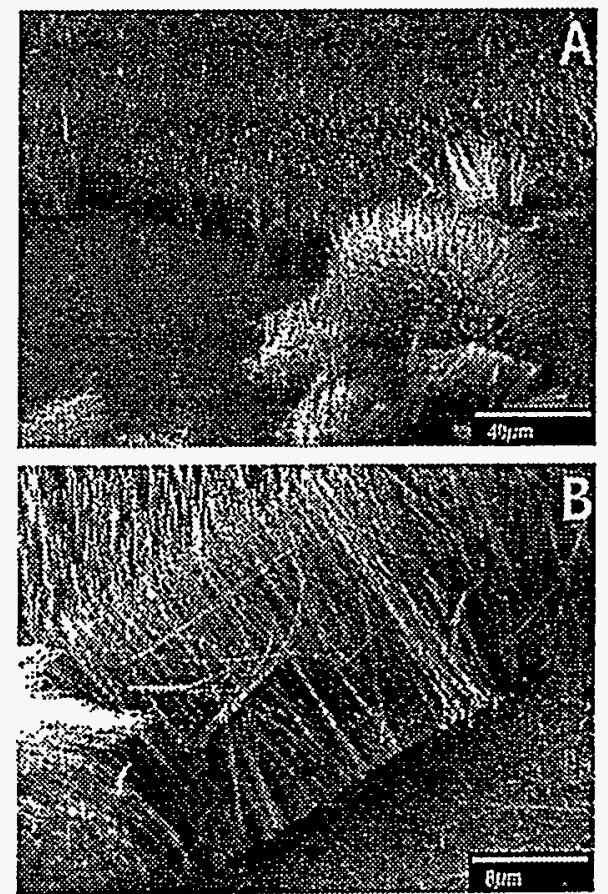

Fig. 1. (A) SEM micrograph of carbon nanotubes aligned perpendicular to the substrate over large areas; growth conditions are listed in Table 1. (B) Enlarged view of (A) along the peeled edge showing diameter, length, straightness, and uniformity in height, diameter, and site density. bon nanotubes grown on nickel-conted display glass. The growth conditions used are listed in Table 1. In the first experiment, $\mathrm{NH}_{3}$ was introduced during the first $5 \mathrm{~min}$ without introducing $\mathrm{C}_{2} \mathrm{H}_{2}$. During this time, plasma etching was used to reduce the thickness of the nickel layer, resulting in a thickncss of $<40 \mathrm{~nm}$. After these initial $5 \mathrm{~min}, \mathrm{C}_{2} \mathrm{H}_{2}$ was introduced. Immediately a color change occurred, as a result of the growth of carbon nanotubes. The growth period lasted only 10 min. In order to examine the orientation and alignment of the carbon nanotubes on the glass substrates, part of the carbon nanotubecovered area was peeled off (Fig. IA, lower left) with tweezers to expose the glass substrate. During peeling, another area was crumpled (Fig. IA, lower right), and a long scratch was made on the peeled open area (Fig. IA, lower left). Under visual and SEM observations, the alignment of the carbon nanotubes across the whole surface was as uniform as in the upper part of Fig. IA. To estimate the carbon nanotube length, an SEM inage was taken at higher magnification
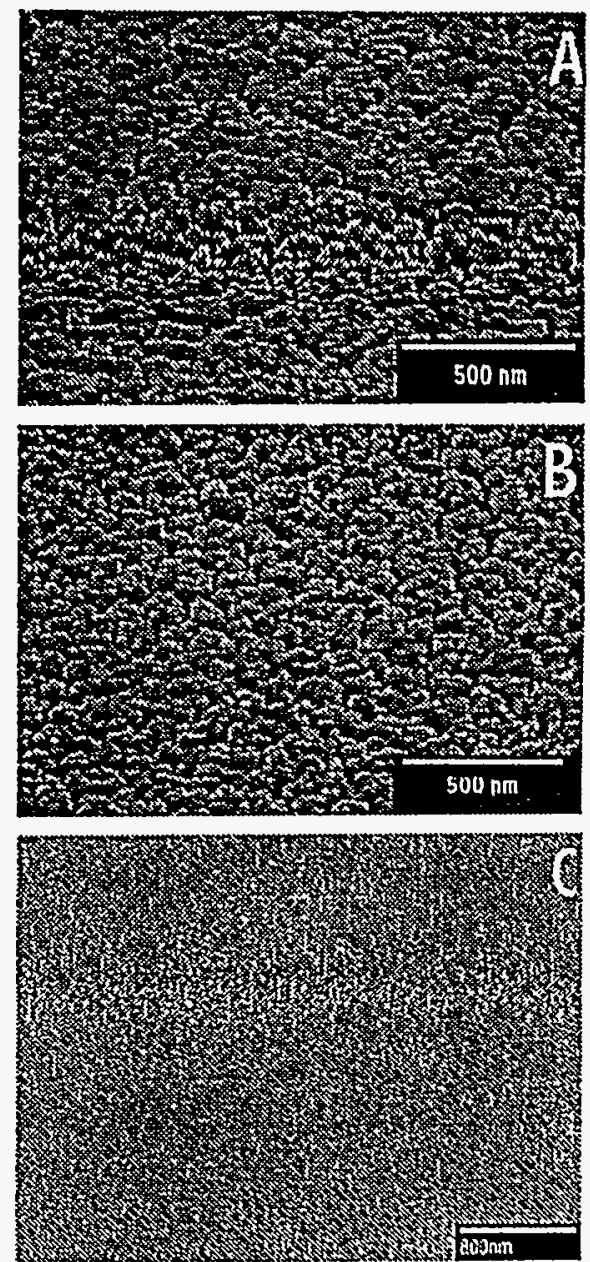

Fig. 2. SEM surface morphology of the nickel layers. (A) Etched by $\mathrm{NH}_{3}$ plasma for $3 \mathrm{~min}$. (B) Etched by $\mathrm{N}_{2}$ plasma for $3 \mathrm{~min}$. (C) As-sputtered smooth surface. 


\section{DISCLAIMER}

This report was prepared as an account of work sponsored by an agency of the United States Government. Neither the United States Government nor any agency thereof, nor any of their employees, make any warranty, express or implied, or assumes any legal liability or responsibility for the accuracy, completeness, or usefulness of any information, apparatus, product, or process disclosed, or represents that its use would not infringe privately owned rights. Reference herein to any specific commercial product, process, or service by trade name, trademark, manufacturer, or otherwise does not necessarily constitute or imply its endorsement, recommendation, or favoring by the United States Government or any agency thereof. The views and opinions of authors expressed herein do not necessarily state or reflect those of the United States Government or any agency thereof. 


\section{DISCLAIMER}

Portions of this document may be illegible in electronic image products. Images are produced from the best available original document. 
Table 1. Growth conditions for nanotubes as shown in Figs. 1 through 4.

\begin{tabular}{|c|c|c|c|}
\hline $\begin{array}{l}\mathrm{C}_{2} \mathrm{H}_{2} / \mathrm{NH}_{3} / \mathrm{N}_{2} \\
\quad(\mathrm{SCCM})\end{array}$ & $\begin{array}{l}\text { Filament } \\
\text { current (A) }\end{array}$ & $\begin{array}{l}\text { Plasma intensity } \\
\text { (A/V/W) }\end{array}$ & $\begin{array}{l}\text { Growth time } \\
(\min )\end{array}$ \\
\hline $\begin{array}{l}\text { Fig. } 1, A \text { and } B \\
0 / 160 / 0 \text { followed by } 80 / 160 / 0\end{array}$ & $\begin{array}{l}8.5 \\
8.5\end{array}$ & $\begin{array}{l}0.10 / 635 / 72 \\
0.13 / 670 / 95\end{array}$ & $\begin{array}{r}5 \\
10\end{array}$ \\
\hline $\begin{array}{l}\text { Fig. 2A } \\
0 / 160 / 0 \\
\text { Fig. } 2 B\end{array}$ & 8.5 & $0.09 / 740 / 66$ & 3 \\
\hline $\begin{array}{l}0 / 0 / 296 \\
\text { Fig. } 3, A \text { and } B\end{array}$ & 8.5 & $0.10 / 480 / 53$ & 3 \\
\hline $\begin{array}{l}80 / 160 / 0 \\
\text { Fig. } 4 \mathrm{~A}\end{array}$ & 8.5 & $0.20 / 700 / 150$ & 25 \\
\hline $\begin{array}{l}40 / 160 / 0 \\
\text { Fig. } 4 B\end{array}$ & 7.2 & $0.13 / 650 / 90$ & 14 \\
\hline $0 / 160 / 0$ followed by $80 / 160 / 0$ & $\begin{array}{l}8.0 \\
8.2\end{array}$ & $\begin{array}{l}0.10 / 480 / 52 \\
0.10 / 560 / 60\end{array}$ & $\begin{array}{l}20 \\
10\end{array}$ \\
\hline
\end{tabular}

along the peeled edge (Fig. 1B). Misalignment of the carbon nanotubes on the peeled edge is a result of the peeling operation. From Fig. 1B, it was estimated that the nanotubes were about $100 \mathrm{~nm}$ in diameter and $20 \mu \mathrm{m}$ in length. Given the growth time of $10 \mathrm{~min}$, the growth rate was calculated to be $120 \mu \mathrm{m} /$ hour, which is about five times faster than the value reported in (7). When the sequence of gas introduction was reversed (that is, when $\mathrm{C}_{2} \mathrm{Il}_{2}$ was introduced first, followed by $\mathrm{NH}_{3}$ 5 min later), no growth of carbon nanotubes was observed; only amorphous carbon was formed on the nickel surface under these conditions. The amorphous carbon layer formed in the first $5 \mathrm{~min}$ in $\mathrm{C}_{2} \mathrm{H}_{2}$ plasma covered the nickel surface and prevented the catalytic role of nickel, so that there was no growth of carbon nanotubes. It seems that the carbon nanotubes grow only when $\mathrm{NH}_{3}$ is introduced first, followed by $\mathrm{C}_{2} \mathrm{H}_{2}$, or when both $\mathrm{C}_{2} \mathrm{H}_{2}$ and $\mathrm{NH}_{3}$ are introduced at the same time. We conclude that $\mathrm{NH}_{3}$ plays a crucial catalytic role together with the nickel layer to promote the growtly of the carbon nanotubes. The catalytic role of $\mathrm{NH}_{3}$ was further confinned by the fact that there was also no carbon nanotube growth when $\mathrm{NH}_{3}$ was replaced by $\mathrm{N}_{2}$ gas, with the other conditions unchanged. The surface of the nickel layer aller the initial $\mathrm{NII}_{3}$ or $\mathrm{N}_{2}$ plasma elching was essentially the same (Fig. 2, A and B, respectively). The plasma etcling conditions are listed in Table 1. For comparison, Fig. 2C shows the as-sputtered smooth nickel surface. It is clcarly shown that both $\mathrm{NH}_{3}$ and $\mathrm{N}_{2}$ plasma ctching roughen the nickel surface, but the roughing of the nickel surfice is not responsible for the nuclcation and growth of carbon nanotubes.

In order to examine the effect of the thickness of nickel layer on the growth of carbon nanotubes, $\mathrm{C}_{2} \mathrm{H}_{2}$ and $\mathrm{NH}_{3}$ were introduced at the same time in the second experiment (Tabie 1). Under these growth conditions, no nlasma etching occurred and the nickel laver remained $40 \mathrm{~nm}$ thick. The diameters of the carbon nanotubes (Fig. 3A) were much large than those shown in Fig. IB. From Fig. 3B, we estimate that the outside diameters of the carbon nanotubes ranged from 180 to $350 \mathrm{~nm}$ and that most of the carbon nanotubes were about $250 \mathrm{~nm}$ in diameter. This experiment clearly shows that nickel thickness plays a very important role in determining the diameters of the carbon nanotubes. The catalytic role of nickel is also clcarly shown by the
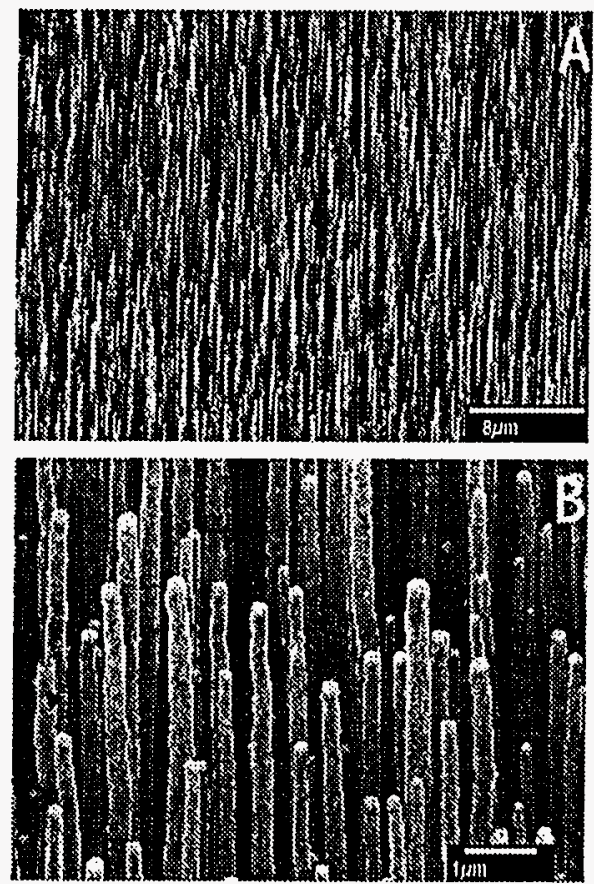

Fig. 3. (A) SEM micrograph of carbon nanotubes grown as in Table 1 . The diameters are clearly larger than those shown in Fig. 1B. (B) Enlarged view of (A) showing the diameters and their distributions. A site density of about $10^{7}$ tubes $/ \mathrm{mm}^{2}$ was estimated. The nickel cap of one nanotube located at the left is missing, as indicated by the arrow. Because the nickel cap is absent, the tube is transparent and the nanotwhe hehind it is vicihle through the wall nickel cap on the tip of each nanotube (Fig. $3 \mathrm{~B}$ ). One carbon nanotube, indicated by an arrow in Fig. 3B, did not have a nickel cap. We conclude that the carbon nanotubes were empty and had very thin walls, because another carbon nanotube is visible behind the capless one through its wall. These large carbon nanotubes may be useful for applications such as storage of $\mathrm{H}_{2}$ and other gases (18).

These experiments show that the thinner the nickel layer, the thinner the nanotubes. To examine further the effect of nickel layer thickness on carbon nanotube growth, another pair of experiments was started with a nickel layer of only $15 \mathrm{sm}$ (Table 1). In one experiment, we again used plasma etching to reduce the nickel thickness by introducing $\mathrm{NH}_{3}$ first and introducing $\mathrm{C}_{2} \mathrm{H}_{2} 20$ min later. SEM micrographs of carbon nanotubes grown under the conditions listed in Table 1 (Fig. 4, A and B) show clearly that the diameters of the nanotubes are dependent on the nickel layer thickness. The typical diameter in Fig. $4 \mathrm{~A}$ is only about $65 \mathrm{~nm}$, as compared to $240 \mathrm{~nm}$ in Fig. 3B. In addition, the alignment in Fig. $4 \mathrm{~A}$ is not as good as in Fig. 3B. A comparison of Figs. $4 A$ and $4 B$ demonstrates that $20 \mathrm{~min}$ of plasma etching reduced the thickness of nickel layer, which in turn

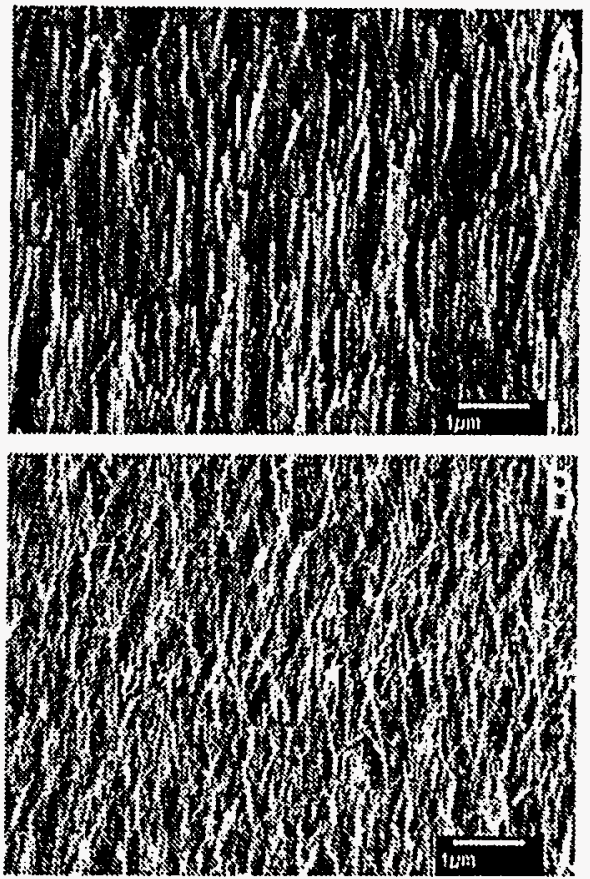

Fig. 4. (A) SEM micrograph showing that thinner carbon nanotubes were grown on thimner (15-nm) nickel-coated glass. The alignment is not as good as that in Fig. 3B. Growth conditions for this sample are listed in Table 1. (B) SEM micrograph showing carbon nanotubes with diameters as low as $20 \mathrm{~nm}$, grown under the growth conditions listed in Table 1. The image demonstrates that when the nanotube diameters nanotubes continue to decrease, thair alinnmont ic orradually lnet 


\section{REPORT S}
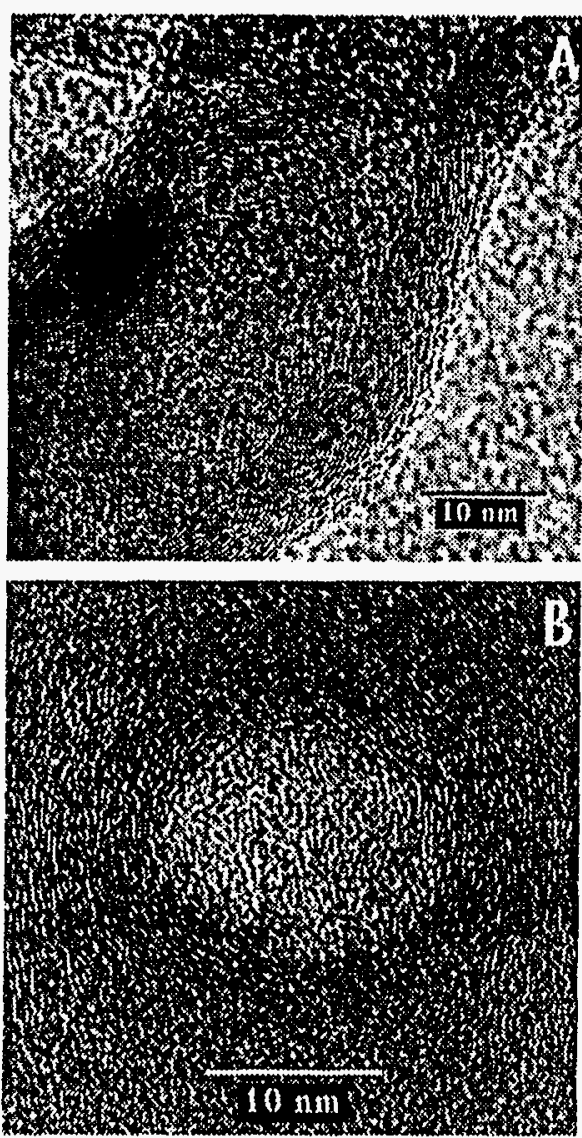

Fig. 5. HRTEM images showing the interior and wall structures of a typical thin carbon nanotube. (A) Cross-section view. (B) Plan view.

resulted in even thinner carbon nanotubes with typical diameters of only about $20 \mathrm{~nm}$. The comparison also shows that the alignment starts to worsen drastically when the nanotube diameter is reduced to $20 \mathrm{~nm}$. Thereforc, for applications requiring good alignment, diameters should be larger than $50 \mathrm{~nm}$.

We used high-resolution transmission electron microscopy (HRTEM) to determine the interior and wall structures of the carbon nanotubes (19). Figure 5A shows a crosssection view of a typical thinner carbon nanotube. The outside diameter of this carbon nanotube is nearly $30 \mathrm{~nm}$. It clearly shows that the nanotube is a multiwalled centrally hollow tube, not solid fiber. The fringes on each side of the tube represent individual cylindrical graphitic layers. This particular carbon nanotube is a structure with approximately 15 walls of graphitized carbon. Both the angular bend in the structure and the appearance of carbon walls running across the diameter of the nanotube demonstrate structural defects suggestive of twisting of the nanotube structure. The lack of fringes inside the tube, as well as the lighter contrast as compared to the nanotube walls, indicate that the core of the structure is hollow.

Firther evidence of a hallow ente is shown in Fig. 5B. This is a plan view IIR'TEM image of a single carbon nanotube structure (19). Here we can more clearly see the hollow nature of the nanotube, again represented by the lighter contrast of the inner core. The disorder seen in the wall fringes circumventing the hollow center is most likely caused by the twistlike defects throughout the carbon nanotube length, as shown in Fig. 5A. These HRTEM images definitely show that the structures reported in this paper are hollow multiwalled carbon nanotubes with defects existing along the tube. The defects of bending and twisting of the thin carbon nanotubes shown in Fig. 5, A and B, are consistent with the SEM observation shown in Fig. 4B.

The growth mechanism of aligned carbon nanotubes is ascribed in the literature to constraint of the pores in either mesoporous silica (7) or laser-etched tracks (8). However, in our experiments the alignment of the carbon nanotubes cannot be duc to pores (7) or etched tracks $(8)$ because there are no pores (7) or etched tracks ( 8 ) in our glass substrates, but is rather due to a nanotube nucleation process catalyzed by ammonia and nickel. In the presence of ammonia, each nickel cap efficiently catalyzes the continuous synthesis of carbon nanotubes. As the nanotubes grow, the nickel cap remains on the tip of each. The alignment and thickness of the carbon nanotubes may be determined by the oricntation and sizc, respectively, of the initial catalytic centers. With this method, we can envision the synthesis of large panels of well-aligned carbon nanotubes for use in many applications.

\section{References and Notes}

1. S. lijlma, Nature 354, 56 (1991)

2. A. Thess et al., Science 273, 483 (1996).

3. C. Journet et al., Nature 388, 756 (1997)

4. J. Liu et al, Sclence 280, 1253 (1998).

5. J. C. Charlier, A. De Vita, X. Blast, R. Car, lbid, 275. 646 (1997).

6. W. A. de Heer et al., lbid. 268, 845 (1995).

7. W. Z. Llet al., Ibld. 274, 1701 (1996). in this method, the substrate was prepared by a sol-gel process from tetraethoxysilane hydrolysis in iron nitrate aqueous solution. The gel was then calcined for 10 hours at $450^{\circ} \mathrm{C}$ at $10^{-2}$ torr. A sillca network with relatively uniform pores was obtained, having iron oxide nanoparticles embedded in the pores. The iron oxide nanoparticles were then reduced at $550^{\circ} \mathrm{C}$ in 180 torr of flowing $9 \% \mathrm{H}_{2} / \mathrm{N}_{2}\left(110 \mathrm{~cm}^{3} / \mathrm{min}\right)$ for 5 hours to obtain iron nanoparticles. The nanotubes grew along the direction of the pores. Only the nanotubes grown out of the vertical pores were aligned. The Iron particles on the surface and in the inclined pores resulted in misorlented nanotubes. The alignment was due to the constraint of the vertically aligned pores.

8. M. Terrones et al., Nature 388, 52 (1997).

9. W. A. de Heer, A. Chatelain, D. Ugarte, Science 270 1179 (1995).

10. A. G. Rinzler et al., ibld. 269, 1550 (1995).

11. Q. H. Wang et al., Appl. Phys. Lett. 72, 2912 (1998).

12. P. G. Collins, A. Zettl, H. Bando, A. Thess, R. E. Smalley, Science 278, 100 (1997).

13. S. Frank, P. Poncharal, Z. L. Wang. W. A. de Heer, Ibid. 280, 1744 (1998)

14. T. W. Ebbesen, Carbon Nanotubes: Preparation and Dmortiace (rRe Prase Rnra Ratrn Fi 1007)
15. L. C. Lapp, D. M. Moffatt, W. H. Dumbaugh, P. L Bocko, product information, Corning. The display glass substrates used in this paper were supplied by Corning for testing purpose only, Information about the detalled properties can be obtained from Corning. The most important property of the flat-panel display glass is the high strain point of $666^{\circ} \mathrm{C}$, as compared to the strain point of $500^{\circ}$ to $590^{\circ} \mathrm{C}$ of commercial glasses.

16. Z. P. Huang et al., in preparation.

17. Before the deposition of the nickel layer, display glass was cut into pieces measuring $10 \times 5 \mathrm{~mm}$ and then cleaned in acetone by ultrasonication. The cleaned pleces were mounted on the surface of a stainless steel resistive heater, and the whole assembly was introduced into the sputtering chamber. The chamber was then pumped down below $8 \times 10^{-6}$ torr before argon gas was introduced into the chamber to maintain a working pressure of 20 to 60 millitorr. During deposition, the substrates were either heated or kep at room temperature. The deposition of the nickel layer lasted only from 1.5 to $6 \mathrm{~min}$ and produced nickel layers from 15 to $60 \mathrm{~nm}$ In thickness. After the nickel layers were deposited, the substrates were transferred to a chemical vapor depositlon chamber and pumped down below $6 \times 10^{-6}$ torr. As soon as the chamber pressure reached $6 \times 10^{-6}$ torr, acetylene and ammonia gases were introduced into the chamber to maintain a working pressure of 1 to 20 torr during carbon nanotube growth. The total flow rate of acetylene and ammonia gases was 120 to 200 standard cublc centimeters per minute (SCCM), with a volume ratio of acetylene to ammonia varying from $1: 2$ to $1: 10$ in different experimental runs. After the working pressure had been stabilized, the power to the tungsten filament coil and that to the plasma generator were tumed on to generate heat and plasma. Under the present experimental setup, the temperature of samples is estimated to be below $666^{\circ} \mathrm{C}$ because there was no visually noticeable change of the glass due to heating. The growth period ran from 5 to $20 \mathrm{~min}$. After growth, the samples were taken out and transferred to a scanning electron microscope (Hitachl 5-4000) for examination of nanotube alignment, diameter, length, straightness, site density and uniformity, and so on. Typical samples with good alignment were also examined by $x$-ray diffraction. Raman spectroscopy, $x$-ray photoemission spectros. copy and HRTEM to study the structure, crystallinity. composition, central core diameter, and tube wall structures.

18. A. Dillon et al., Nature 386, 377 (1997); G. E. Gadd et al. Science 277, 933 (1997).

19. HRTEM was performed on JEOL 2010 in the Earth and Planetary Science Department at the University of New Mexico, Albuquerque, NM. Samples for plan view HRTEM were prepared as follows: Given the

C) flexible nature of the nanotubes, we penetrated the films with M-Bond 610 epoxy resin (M-Line Accessories, $\bullet \bullet, \bullet \bullet)$ to provide mechanical stiffness. It has very low viscosity and curing is time and temperature dependent. Hydrotetrafuran (diethylene oxlde) makes up about $90 \%$ of the composition of M-bond. The carbon nanotube film was immersed in acetone, then M-Bond epoxy was added slowly until a 1:1 ratio was attained. The sample cured at room temperature for 48 hours. The viscosity of the epoxy is very low when introduced to the sample, so it easily impregnates pores and completely mixes with the acetone. Standard mechanical thinning and ion milling (low angle, voltage, and current) were used to thin the sample to electron transparency. Most of the substrate was removed mechanlcally, followed by ion milling until the film was exposed. Then both sides were ton milled for 15 min. Under contract DAAG5

20. This material is based on work/supported in part by the U.S. Amy Research Office The management of this program by R. R. Reeber is greatly appreclated. The authors also thank $G$. Sagerman for his technical support. Sandla is a multiprogram laboratory operated by Sandia Corporation, a Lockheed Martin Company, for the U.S. Department of Energy under contract DE-AC04-94AL8500. 